1 School of Biological Sciences, Food Sciences Division, University of Nottingham, Sutton Bonington Campus, Leicestershire LE12 5RD, UK

2 Centre for Applied Microbiology and Research (CAMR), Research Division, Porton Down, Salisbury SP4 0JG, UK

3 PHLS Food Microbiology Food Research Unit, Church Lane, Heavitree, Exeter EX2 5AD, UK

\section{Invasiveness in chickens, stress resistance and RpoS status of wild-type Salmonella enterica subsp. enterica serovar Typhimurium definitive type 104 and serovar Enteritidis phage type 4 strains}

\author{
Frieda Jørgensen, ${ }^{1,3}+$ Steve Leach, ${ }^{2}$ Stephen J. Wilde, ${ }^{3}$ Angela Davies, ${ }^{2}$ \\ Gordon S. A. B. Stewart ${ }^{1} \neq$ and Tom Humphrey ${ }^{3}$
} Author for correspondence: Frieda Jørgensen. Tel: +44 1392 402955. Fax: + 441392412835.
e-mail: fjorgensen@phls.org.uk

The heat and acid resistance and the ability to survive airdrying on commonly used kitchen surfaces were assessed for clinical and environmental strains of Salmonella enterica subsp. enterica serovar Typhimurium, definitive type (DT) 104. Three out of thirty-eight strains of DT 104 were found to be more sensitive in stationary phase to the stresses examined than the other strains. This compares to a previous study by the authors which showed that seven out of forty serovar Enteritidis phage type (PT) 4 strains were more sensitive. RpoS activity was examined indirectly in selected strains of DT 104 and PT 4. In those with normal stress resistance a 100-fold induction of an RpoS-dependent SpvRIA': : IUXCDABE fusion was observed upon entry into stationary phase. The sensitive strains examined showed either no induction or a reduced level of spvRIA': IuxCDABE expression. The rpoS gene was sequenced from these strains and three were found to harbour mutations including one deletion, one base-pair substitution resulting in a nonsense codon, and one insertion causing a frameshift resulting in an early stop codon. Strains with negligible or reduced spvRIA': : luxCDABE expression had low stress resistance. All strains of DT 104 could be recovered from liver and spleen tissues of infected hens $14 \mathrm{~d}$ post-infection, but one with no induction of spvRIA': IUxCDABE expression was significantly less likely to be recovered from chicken reproductive tissues, liver or spleen than the majority of other strains, including one with reduced SpvRIA': : IuxCDABE expression. This work has demonstrated that clinical and environmental strains of DT 104 and PT 4 not infrequently harbour mutations in the rpos allele. It is possible that the rpos mutations may have occurred during the initial isolation of the strains. The ability of a strain to cause infection, however, also depends on factors such as host susceptibility and dose.

Keywords: $s p v$-lux reporter, chicken reproductive tissue

\section{INTRODUCTION}

Within the past 10 years, the prevalence of salmonellosis

Present address: PHLS Food Microbiology Food Research Unit, Church
Lane, Heavitree, Exeter EX2 5AD, UK.
‡Professor Stewart sadly died in February 1999, at age 47 .

Abbreviations: DT, definitive type; PT, phage type; RLU, relative light units (per $\mathrm{ml}$ ). has shown a marked increase in Europe and much of the rest of the developed world. Salmonella enterica subsp. enterica serovar Enteritidis (S. enteritidis) has become the predominant strain. One particular phage type (PT) of $S$. enteritidis, PT 4, has been the most common cause of foodborne salmonellosis for nearly a decade in Western Europe and has also been linked to an increasing number of cases of food poisoning in the USA (Altekruse et al., 1997). Another very prevalent Sal- 
monella strain associated with human infections worldwide is Salmonella enterica subsp. enterica serovar Typhimurium (S. typhimurium) definitive type (DT) 104 (Anonymous, 1997). Together PT 4 and DT 104 currently account for over $70 \%$ of all confirmed cases of salmonellosis in England and Wales (Anonymous, 1999).

More than $90 \%$ of DT 104 strains show multiple antibiotic resistance and $\sim 15 \%$ carry resistance to quinolones (Wall et al., 1994; Threlfall et al., 1996). This may cause therapeutic problems, as fluoroquinolones are the drugs of first choice for treating extra-intestinal and serious intestinal complications of human and animal salmonellosis. DT 104 has a broad spectrum of hosts and can easily spread to many different domestic and wild animals. Outbreaks of DT 104 and PT 4 infection have been associated with a number of food vehicles including poultry meat and eggs (Wall et al., 1994; Coyle et al., 1988; Rampling et al., 1989). A better understanding of the mechanisms by which these foodborne pathogens survive in the environment and colonize chickens will provide the basis for designing more effective intervention strategies.

In previous studies, the resistance of $40 \mathrm{PT} 4$ strains to heat, acid and hydrogen peroxide, as well as the ability to survive airdrying on commonly used kitchen surface materials was examined (Humphrey et al., 1995). The studies identified a small subgroup of strains that were much more sensitive to these stresses than the majority. These strains also showed differences in their ability to invade chicken tissues, particularly those of the reproductive tract (Humphrey et al., 1996). Like PT 4, DT 104 has been shown, under experimental conditions, to be able to contaminate egg contents and can also be isolated from muscle tissue in laying hens (Williams et al., 1998; Leach et al., 1999). Little is known about the ability of DT 104 to invade other tissues, or whether a spectrum of invasiveness exists.

The $r p o S$-encoded $\sigma^{\mathrm{S}}$ subunit of RNA polymerase is an important regulator of the general stress response and is also required for virulence in S. typhimurium in orally infected mice (Loewen \& Hengge-Aronis, 1994; Mahan et al., 1996; Fang et al., 1992) but less is known about the role of rpoS in the systemic infection of chickens.

The principal aim of the present study was to assess the ability of naturally occurring DT 104 strains to invade tissues in laying hens and relate this to their RpoS status and ability to survive exposure to drying, low $\mathrm{pH}$ and heat. We demonstrate variation in the ability to invade and/or persist in different chicken tissues among the DT 104 strains. Stress-sensitive strains were present among the DT 104 strains but these strains were not all less invasive. A majority of stress-sensitive DT 104 and PT 4 strains harboured mutations in the rpoS gene or showed reduced expression of the RpoS protein as measured indirectly using the RpoS-dependent $s p v R / A^{\prime}:: \operatorname{lux} C D A B E$ fusion. The significance of the rpoS gene for the contamination of egg contents is discussed.

\section{METHODS}

Bacterial strains and phenotypic screens. The DT 104 strains described in Table 1 originated from unrelated human cases, various environmental sources and food animals and are held in a strain collection at the Public Health Laboratory Service (PHLS) Food Microbiology Research Unit, Exeter, UK. The PT 4 strains examined have previously been described (Humphrey et al., 1995). All strains contain the Salmonella virulence plasmid which carries the virulence genes spvRABCD (Gulig et al., 1993). The strains received very limited subculture after initial isolation and were maintained as frozen stocks at $-70^{\circ} \mathrm{C}$ on Cryobeads (Prolab Diagnostics). Cultures were grown at $37^{\circ} \mathrm{C}$ to stationary phase in nutrient broth (NB, Oxoid CM 67) as described previously (Humphrey et al., 1995). Phenotypic screens of 38 DT 104 strains were essentially performed according to the techniques described by Humphrey et al. (1995), with some minor modifications. Heat resistance was assessed after $15 \mathrm{~min}$ at $52{ }^{\circ} \mathrm{C}$ instead of $10 \mathrm{~min}$; survival on Formica surfaces at $20^{\circ} \mathrm{C}$ in $0.02 \mathrm{ml}$ blood was assessed after $72 \mathrm{~h}$ instead of $24 \mathrm{~h}$; acid resistance was assessed after 5 min at $\mathrm{pH} 2 \cdot 8$ instead of $\mathrm{pH} 2 \cdot 6$. Experiments determining heat and acid resistance were performed in duplicate while experiments to determine survival in blood on Formica were performed in triplicate. Differences in stress resistance of the strains were examined for statistical significance using ANOVA in Microsoft Excel.

Oral infection of chickens. Point-of-lay Hisex Brown pullets (17 weeks old) were obtained from a commercial Salmonellafree source. Faecal samples were tested prior to infection of the birds to confirm that they were free of Salmonella spp. The inoculum for each strain was grown in NB to stationary phase as previously described (Humphrey et al., 1996). Fifteen birds were infected with each strain via the crop with $0.5 \mathrm{ml}$ of culture diluted to contain approximately $10^{7}$ c.f.u. (confirmed retrospectively) as described previously (Humphrey et al., 1996). The birds were housed singly in cages following infection. Birds were examined at least daily for signs of illness, and faeces were collected every other day. On day 14 post-infection, the chickens were killed and entire liver, spleen, oviduct and ovary samples collected from each bird. All the work necessitating the involvement of animals was carried out with due concern for their welfare, in strict accordance with the Home Office Animals (Scientific Procedures) Act 1986 and subject to Local Ethical Committee approval.

Care was taken to ensure the aseptic removal of each organ. Birds were first surface-decontaminated using sodium hypochlorite solution. The body cavity was opened and the tissues removed in the following order: liver, spleen, oviduct and ovary. Fresh sterile surgical instruments were used for each bird and, on removal, each organ was immediately transferred to an individual sterile stomacher bag. Faeces and tissue samples were examined for the presence of Salmonella spp. using previously described methods (Humphrey et al., 1996). Briefly, tissue samples were weighed and then homogenized using a stomacher in Maximum Recovery Diluent (MRD; Oxoid CM733). Liver and spleen homogenates were then serially diluted in MRD and plated onto xylose lysine desoxycholate (XLD; Oxoid CM 469) agar for microbiological counts. Remaining homogenates of liver and spleen, and those of ovary and oviduct, were also examined for the presence of Salmonella spp. using standard pre-enrichment and enrichment techniques. Faecal samples were selectively enriched in selenite broth (Oxoid CM 699) and plated onto XLD agar. The infection experiment was performed twice with strains 30,11, 10 and 41 and once with strains 27, 16, 34 
Table 1. S. typhimurium DT 104 strains

\begin{tabular}{|c|c|c|c|}
\hline Strain & $\begin{array}{c}\text { Tolerance } \\
\text { profile* }\end{array}$ & $\begin{array}{c}\text { Antibiotic } \\
\text { resistance } \\
\text { profile } \dagger\end{array}$ & Source \\
\hline 30 & $\mathrm{R}$ & SuT & Bovines \\
\hline 10 & $\mathrm{~S}$ & ACSSuT & Human \\
\hline 11 & S & SuT & Human \\
\hline 41 & $\mathrm{~S}$ & ACSSuT & Human \\
\hline 27 & $\mathrm{R}$ & ACSSuTTm & Chicken \\
\hline 34 & $\mathrm{R}$ & ACSSuT & Human \\
\hline 16 & $\mathrm{R}$ & SuT & Sewage \\
\hline 31 & $\mathrm{R}$ & SuT & Bovines \\
\hline 12 & $\mathrm{R}$ & ACSSuT & Human \\
\hline 13 & $\mathrm{R}$ & ACSSuT & Sewage \\
\hline 14 & $\mathrm{R}$ & ACSSuT & Milk \\
\hline 15 & $\mathrm{R}$ & ACSSuT & Human \\
\hline 17 & $\mathrm{R}$ & ACSSuT & Environment \\
\hline 18 & $\mathrm{R}$ & ACSSuT & Sewage \\
\hline 19 & $\mathrm{R}$ & ACSSuT & Human \\
\hline 20 & $\mathrm{R}$ & ACSSuT & Water \\
\hline 21 & $\mathrm{R}$ & ACSSuTTm & Water \\
\hline 22 & $\mathrm{R}$ & ACSSuT & Sewage \\
\hline 23 & $\mathrm{R}$ & ACSSuTTm & Water \\
\hline 24 & $\mathrm{R}$ & ACSSuT & Bovines \\
\hline 25 & $\mathrm{R}$ & ACSSuT & Bovines \\
\hline 26 & $\mathrm{R}$ & ACSSuT & Bovines \\
\hline 28 & $\mathrm{R}$ & ACSSuT & Sewage \\
\hline 29 & $\mathrm{R}$ & SuT & Bovines \\
\hline 32 & $\mathrm{R}$ & SuT & Human \\
\hline 35 & $\mathrm{R}$ & ACSSuT & Human \\
\hline 36 & $\mathrm{R}$ & ACSSuT & Human \\
\hline 37 & $\mathrm{R}$ & ACSSuT & Human \\
\hline 38 & $\mathrm{R}$ & ACSSuT & Human \\
\hline 39 & $\mathrm{R}$ & ACSSuT & Human \\
\hline 40 & $\mathrm{R}$ & SuT & Human \\
\hline 43 & $\mathrm{R}$ & ACSSuT & Human \\
\hline 44 & $\mathrm{R}$ & ACSSuTTm & Human \\
\hline 45 & $\mathrm{R}$ & ACSSuTTm & Human \\
\hline 46 & $\mathrm{R}$ & ACSSuTTm & Human \\
\hline 47 & $\mathrm{R}$ & ACSSuTCp & Human \\
\hline 48 & $\mathrm{R}$ & ACSSuTCp & Human \\
\hline 49 & $\mathrm{R}$ & ACSSuTCp & Human \\
\hline 50 & $\mathrm{R}$ & ACSSuT & Human \\
\hline
\end{tabular}

* The classification of the strains as overall resistant $(\mathrm{R})$ or sensitive ( $\mathrm{S}$ ) was based on the following tests. Acid resistance (\% survival after $5 \mathrm{~min}$ at $\mathrm{pH} 2 \cdot 8$ ) was determined in 39 strains; strains were classified as acid resistant when $\geqslant 25 \%$ survived and as sensitive when $<10 \%$ survived. Heat resistance (\% survival after $15 \mathrm{~min}$ at $52^{\circ} \mathrm{C}$ ) was determined in 37 strains; strains were classified as heat resistant when $>20 \%$ survived and as sensitive when $<4 \%$ survived. Survival on surfaces $(\%$ survival after $72 \mathrm{~h}$ at $20^{\circ} \mathrm{C}$ on a Formica surface) was determined in 22 strains; strains were classified as resistant when $>20 \%$ survived and as sensitive when $\leqslant 6 \%$ survived.

† A, ampicillin $10 \mu \mathrm{g}$; C, chloramphenicol $2 \cdot 5 \mu \mathrm{g}$; S, streptomycin $25 \mu \mathrm{g}$; Su, sulphamethoxazole $25 \mu \mathrm{g}$; Tm, trimethoprim $10 \mu \mathrm{g}$; Cp, ciprofloxacin $0 \cdot 1 \mu \mathrm{g}$. and 31. The proportion of Salmonella spp. positive tissues for each strain was compared using the $\chi^{2}$ test with Yates' corrections for small numbers (Statgraphics 5, STSC Inc.).

Expression of bioluminescence. The ability of the DT 104 and PT 4 strains to activate transcription of the $\sigma^{\mathrm{s}}$-dependent $s p v R$ and $s p v A$ promoters was determined by measuring expression of bioluminescence during growth of strains transformed with the plasmids pSB367 or pSB368 (Swift \& Stewart, 1994). Both pSB367 (high copy number) and pSB368 (medium copy number) contain the $s p v R$ gene and a transcriptional fusion luxCDABE (from Photorhabdus luminescens) to the spvA promoter. Expression of the SpvR protein requires an active RpoS protein (Guiney et al., 1995) and the expression of lux $C D A B E$ results from the activation of the $s p v A$ promoter by SpvR and RpoS. The bioluminescence of these strains is, therefore, a measure of active RpoS sigma factor in the cell. The functionality of this system as a reporter for active RpoS levels was shown in Escherichia coli BJ4, where the introduction of a mutation in rpoS reduced light levels by $3 \mathrm{log}$ (Swift \& Stewart, 1994). Preparation of competent cells, electroporation and isolation of bioluminescent colonies was performed according to previously published techniques (Swift et al., 1993). Transformed strains were grown with shaking (200 r.p.m.) in LB broth, Lennox (LB; Difco) at $\mathrm{pH} 7 \cdot 3$. These cultures were standardized to an initial $\mathrm{OD}_{600}$ of 0.025 from overnight cultures and grown at $37^{\circ} \mathrm{C}$ for up to $15 \mathrm{~h}$. Bioluminescence was measured by determining the number of relative light units per $\mathrm{ml}$ (RLU) in scintillation vial inserts ( $4 \mathrm{ml}$; FSA Laboratory Supplies) with a Turner Designs TD-20E luminometer (Streptech) (Swift et al., 1993). Growth of the cultures was measured simultaneously as $\mathrm{OD}_{600}$. Measurement of RpoS expression and $\mathrm{OD}_{600}$ was repeated on two separate occasions for each strain. The $\sigma^{\mathrm{s}}$-dependency of the bioluminescence expressed by the $s p v R / A^{\prime}:: \operatorname{lux} C D A B E$ fusion was validated by measuring the light expressed in three $S$. typhimurium strains with identical backgrounds $(S$. typhimurium LT2) but with different rpoS alleles (strain 4996, rpoS::bla; strain $\chi 3000, r p o S^{\mathrm{LT} 2}$; strain $\chi 8000$, $r p o S^{\text {sL1344 }}$; Wilmes-Riesenberg et al., 1997). In order to confirm that light expression was dependent on the RpoSdependent promoter, light measurements using a constitutive promoter fused to the lux operon (pSB311) were performed with otherwise isogenic $\sigma^{\mathrm{s}}$-positive and $\sigma^{\mathrm{s}}$-negative $S$. typhimurium strains (Hill et al., 1993). In these experiments expression of bioluminescence was constitutively high and showed no growth-phase-dependent induction (results not shown).

Sequence analysis of rpos genes. The rpoS genes were amplified from $S$. typhimurium DT 104 and S. enteritidis PT 4 strains using RPOS5' (5'-CGGAATTCTTATTATCATCAAACATAAC-3') and RPOS3' (5'-CCTTGCCCGGGCTGTGCCGATGCAC-3') amplimers made at the Biopolymer Synthesis and Analysis Unit, University of Nottingham. Template genomic DNA was purified using the ISO-Quick Kit (ORCA Research). PCR amplification was carried out in triplicate, for 30 cycles, each consisting of $30 \mathrm{~s}$ denaturation at $95^{\circ} \mathrm{C}, 1 \mathrm{~min}$ of reannealing at $55^{\circ} \mathrm{C}$ and $2 \mathrm{~min}$ of DNA synthesis at $72^{\circ} \mathrm{C}$. PCR products were separated by electrophoresis, extracted from the gel using a QiaQuick Gel Extraction Kit (QIAGEN), dialysed (Millipore VS filters) and sequenced at the University of Nottingham Sequencing Facility. Each gene was sequenced from at least two independent PCR products and DNA sequences from both strands of the rpoS genes were obtained. 


\section{RESULTS}

\section{Resistance to drying, heat and low pH}

In the present investigation, 38 strains of DT 104 were examined for their ability to survive environmental stresses and were classified as being either sensitive or resistant (Table 1). Three DT 104 strains were classified as sensitive (Table 1). In a previous study of forty PT 4 strains, seven were identified as being significantly more sensitive to these stresses (Humphrey et al., 1995). Strains from the two groups of DT 104 and PT 4 were compared with respect to survival after exposure to heat and acid stress as well as survival on surfaces (Table 2). By ANOVA, no significant differences were observed between the strains classed as resistant, with regard to either heat resistance $\left(\mathrm{F}_{34,35}=0.86, P>0.67\right)$ or acid

Table 2. Comparison of the ability to survive airdrying on surfaces or exposure to heat or acid stress in stationary-phase cultures of S. typhimurium DT 104 and S. enteritidis PT 4

\begin{tabular}{|c|c|c|c|}
\hline \multirow[t]{2}{*}{ Strain } & \multicolumn{3}{|c|}{ Survivors $(\%)^{*}$} \\
\hline & Blood, $20^{\circ} \mathrm{C}, 72 \mathrm{~h}$ & $52^{\circ} \mathrm{C}, 15 \mathrm{~min}$ & pH $2 \cdot 8,5 \mathrm{~min}$ \\
\hline DT 10430 & $33(2.5)$ & $28(2.0)$ & $27(2.0)$ \\
\hline DT 10410 & $2.8(0 \cdot 8)$ & $0 \cdot 17(0 \cdot 1)$ & $6.5(0.5)$ \\
\hline DT 10411 & $6 \cdot 0(0 \cdot 9)$ & $3 \cdot 9(1 \cdot 0)$ & $9 \cdot 0(1 \cdot 4)$ \\
\hline DT 10441 & $5 \cdot 4(1 \cdot 0)$ & $2.7(0 \cdot 8)$ & $8.5(0.5)$ \\
\hline DT 10427 & $39(1 \cdot 0)$ & $23(2.0)$ & $25(2.5)$ \\
\hline DT 10434 & $23(4 \cdot 0)$ & $33(2.0)$ & $35(2.0)$ \\
\hline DT 10416 & $40(11)$ & $29(5 \cdot 0)$ & $36(3 \cdot 0)$ \\
\hline DT 10431 & $32(5 \cdot 0)$ & $25(3 \cdot 0)$ & $32(1 \cdot 5)$ \\
\hline PT 4 E & $36(0 \cdot 9)$ & $36(4 \cdot 0)$ & $42(11)$ \\
\hline PT 4 I & $1 \cdot 1(0 \cdot 4)$ & $2.5(2.0)$ & $6 \cdot 0(1 \cdot 0)$ \\
\hline DT 10412 & $27(3 \cdot 0)$ & $28(6 \cdot 0)$ & $41(9 \cdot 0)$ \\
\hline DT 10413 & ND & $28(1 \cdot 0)$ & $48(5 \cdot 0)$ \\
\hline DT 10414 & $44(5 \cdot 0)$ & $33(5 \cdot 0)$ & $46(14)$ \\
\hline DT 10415 & ND & $26(6 \cdot 0)$ & $38(14)$ \\
\hline DT 10417 & $41(10)$ & $28(5 \cdot 0)$ & $35(6 \cdot 0)$ \\
\hline DT 10418 & $42(10)$ & $22(1 \cdot 0)$ & $43(12)$ \\
\hline DT 10419 & $\mathrm{ND}$ & $41(1 \cdot 0)$ & $41(1 \cdot 0)$ \\
\hline DT 10420 & ND & ND & $38(13)$ \\
\hline DT 10421 & $52(11)$ & $53(12)$ & $53(9 \cdot 0)$ \\
\hline DT 10423 & $49(8 \cdot 0)$ & ND & $34(14)$ \\
\hline DT 10424 & ND & $30(6 \cdot 0)$ & $32(3 \cdot 0)$ \\
\hline DT 10425 & ND & $29(3 \cdot 0)$ & $44(1 \cdot 0)$ \\
\hline DT 10426 & ND & $30(4 \cdot 0)$ & $42(16)$ \\
\hline DT 10428 & $\mathrm{ND}$ & $33(10)$ & $47(18)$ \\
\hline DT 10429 & $38(6 \cdot 0)$ & $30(4 \cdot 0)$ & $35(1 \cdot 0)$ \\
\hline DT 10432 & $35(5 \cdot 0)$ & $31(3 \cdot 0)$ & $43(9 \cdot 0)$ \\
\hline DT 10435 & ND & $26(4 \cdot 0)$ & $37(3 \cdot 0)$ \\
\hline DT 10436 & ND & $32(4 \cdot 0)$ & $47(2.0)$ \\
\hline DT 10437 & $46(4 \cdot 0)$ & $24(2.0)$ & $29(3 \cdot 0)$ \\
\hline DT 10438 & ND & $28(0 \cdot 0)$ & $37(8 \cdot 0)$ \\
\hline DT 10439 & ND & $32(2.0)$ & $37(5 \cdot 0)$ \\
\hline DT 10440 & ND & $36(7 \cdot 0)$ & $29(5 \cdot 0)$ \\
\hline DT 10443 & $56(14)$ & $24(3 \cdot 0)$ & $40(19)$ \\
\hline DT 10444 & ND & $27(2.0)$ & $57(11)$ \\
\hline DT 10445 & ND & $31(5 \cdot 0)$ & $56(4 \cdot 0)$ \\
\hline DT 10446 & $43(8 \cdot 0)$ & $25(3 \cdot 0)$ & $68(11)$ \\
\hline DT 10447 & $33(8 \cdot 0)$ & $27(2.0)$ & $49(13)$ \\
\hline DT 10448 & ND & $23(3 \cdot 0)$ & $56(5 \cdot 0)$ \\
\hline DT 10449 & $395 \cdot 0$ & ND & $39(5 \cdot 0)$ \\
\hline DT 10450 & $365 \cdot 0$ & ND & $59(11)$ \\
\hline
\end{tabular}

ND, Not determined.

*The numbers in parentheses represent the standard error of the mean. 


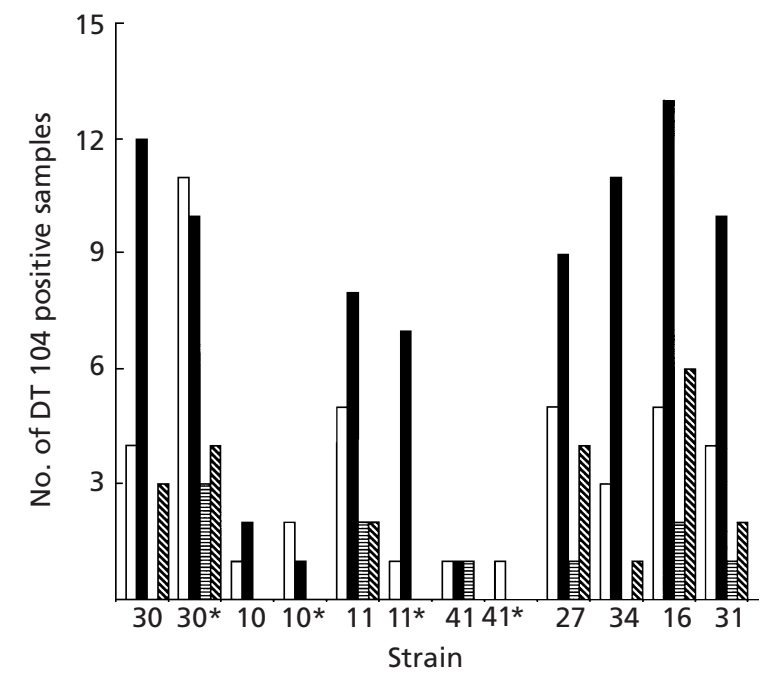

Fig. 1. Invasiveness of S. typhimurium DT 104 strains into liver (open bars), spleen (solid bars), ovary (striped bars) and oviduct (hatched bars). Results show the number of birds with Salmonella-positive tissues, as determined by enrichment culture, out of the 15 in each group that were infected. An asterisk $\left(^{*}\right)$ denotes repeat experiments which were performed with strains $30,10,11$ and 41 only.

resistance $\left(\mathrm{F}_{35,36}=0.94, P>0.58\right)$, or the ability to survive on surfaces $\left(\mathrm{F}_{19,40}=1 \cdot 4, P>0 \cdot 17\right)$. For the DT 104 strains the mean percentage survival values for resistant strains were 28 (SE 0.6), 40 (SE 1.5) and 39 (SE 1.8), respectively, for heat resistance, acid resistance and ability to survive on surfaces, while the corresponding figures for the sensitive strains were 2.2 (SE 1.1), 8 (SE 0.8$)$ and 5.7 (SE 2.1). The difference between the stress-sensitive and -resistant strains was highly statistically significant by ANOVA for both heat $\left(\mathrm{F}_{1,76}=173, P<0.00005\right)$, acid $\left(\mathrm{F}_{1,78}=54, P<0.00005\right)$ and drying on surfaces $\left(\mathrm{F}_{1,70}=89, P<0.00005\right)$.

\section{Invasiveness of DT 104 strains in chicken tissues}

All strains were able to invade liver and spleen tissue in laying hens as determined by enrichment but frequency of recovery from every tissue differed between the strains (Fig. 1). In liver, the numbers of organisms were below the detection limit of the direct count method (i.e. $<10$ cells per $\mathrm{g}$ tissue) for all strains except strain 31 , where a mean count of $\log _{10} 1.4$ per $\mathrm{g}$ of tissue (SD 0.3) was obtained from the three livers which had counts above the detection limit. The number of organisms recovered from spleens was, however, more often sufficiently high to be detected by the direct count method (Table 3). Mean levels of organisms ranged from less than 10 c.f.u. per g, where no direct counts were obtained (strains 10 and 41), to a mean level ranging between $\log _{10} 1.2$ and $\log _{10} 3 \cdot 5$ c.f.u. per $g$ in those tissues where it was possible to establish direct counts (Table 3). Similar levels of Salmonella have been recovered from spleen and liver of chickens infected orally by other workers (Rajashekara
Table 3. Numbers of S. typhimurium DT 104 recovered from spleens, $14 \mathrm{~d}$ post-infection, of chickens orally infected with $10^{7}$ cells

\begin{tabular}{|lcc|}
\hline Strain & $\begin{array}{c}\text { No. of samples } \\
\text { positive by direct } \\
\text { count }(\boldsymbol{n}=15)\end{array}$ & $\begin{array}{c}\text { Mean } \log _{10} \text { c.f.u. per } \\
\text { g tissue of samples } \\
\text { positive by direct } \\
\text { count }(\text { SD })\end{array}$ \\
\hline 30 & 4 & $1 \cdot 2(0 \cdot 3)$ \\
$30^{*}$ & 4 & $1 \cdot 4(0 \cdot 6)$ \\
10 & 0 & - \\
$10^{*}$ & 0 & - \\
11 & 4 & $1 \cdot 2(1 \cdot 0)$ \\
$11^{*}$ & 3 & $1 \cdot 6(0 \cdot 6)$ \\
41 & 0 & - \\
$41^{*}$ & 0 & - \\
27 & 4 & $1 \cdot 2(0 \cdot 7)$ \\
34 & 5 & $3 \cdot 5(0 \cdot 9)$ \\
16 & 10 & $2.0(0 \cdot 5)$ \\
31 & 2 & $1 \cdot 9(0 \cdot 9)$ \\
\hline
\end{tabular}

*Denotes repeat experiments which were performed with strains $30,10,11$ and 41 only.

et al., 2000). Invasion and/or persistence in tissues was, therefore, more reliably established by enrichment techniques, since levels of organisms in tissues $14 \mathrm{~d}$ following oral administration of challenge strains were frequently, though not universally, low. As determined by enrichment (Fig. 1), strains 10 and 41 were found significantly $\left(\chi^{2}\right.$ test, $\left.P<0.001\right)$ less frequently in liver and spleen tissue than strain 30. Strain 10 was not isolated from any ovaries or oviducts. The frequency of isolation from tissues with the stress-sensitive strain 11 was substantially greater than that of strain 10 and not significantly $\left(\chi^{2}\right.$ test, $\left.P>0.05\right)$ reduced by comparison with the majority of the stress-resistant strains $(30,27$, 34,16 and 31). There was a strong positive correlation between the frequency of isolation from liver and isolation from spleen, ovary and oviduct as demonstrated by the significant $P$ values for the linear regression analysis of each of these associations across the different strains $(P=0.04,0.04$ and 0.05 , respectively). This demonstrates that if a DT 104 strain is more frequently isolated from one of these tissues in poultry, such as the liver, it will also be more readily isolated from the others, including the reproductive tissues. Frequency of isolation from any tissue did not correlate with the faecal carriage rates in the DT 104 strains $(P>0.05$; data not shown).

\section{$\sigma^{s}$-dependent gene expression}

The expression from the $\sigma^{\mathrm{S}}$-dependent $s p v R /$ $A^{\prime} l u x$ : : CDABE fusion was determined in three resistant strains $(16,31$ and 30$)$ and a sensitive strain (11) of DT 104. It was not possible to determine RpoS expression using pSB367 or pSB368 in most of the DT 104 strains 

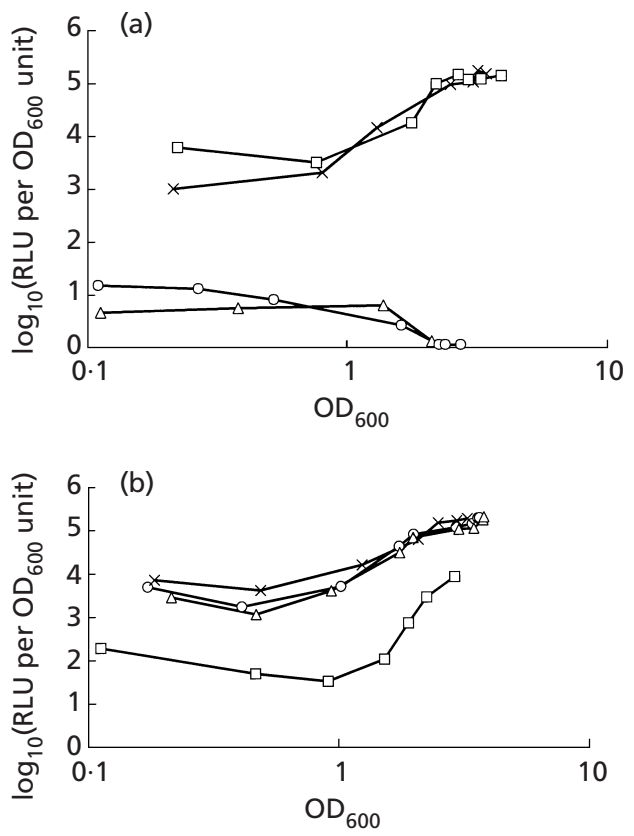

Fig. 2. Expression of the $\sigma^{\mathrm{s}}$-dependent $s p v R / A^{\prime}:: \operatorname{lux} C D A B E$ fusion: (a) in sensitive $(\triangle, \mathrm{l} ; \mathrm{O}, \mathrm{C})$ and resistant $(\square, E ; \times, A)$ strains of $S$. enteritidis PT 4, and (b) in a sensitive strain $(\square, 11)$ and three resistant $(x, 30 ; 0,16 ; \triangle, 31)$ strains of $S$. typhimurium DT 104. Results from representative experiments are shown.

because of an inability to select for the plasmid marker and inherent resistance of these strains to chloramphenicol and ampicillin. Activation of the RpoSdependent fusion was also determined in two resistant (E and A) and two sensitive (I and C) strains of PT 4. In strains classified as resistant, expression of the spvR/A'lux::CDABE fusion demonstrated an induction of promoter activity at the approximate transition between exponential and stationary phases (Fig. 2a, b). The extent of the induction was around 10-100-fold under the conditions used here. In PT 4 strains classified as sensitive, the initial level of light was at least $2 \log _{10}$ lower than in resistant strains and, with no significant induction during the transition into stationary phase, up to a $4 \log _{10}$ difference in light could be observed for cells in the stationary phase (Fig. 2a). DT 104 strain 11 showed a similar level of $\sigma^{\mathrm{s}}$-dependent $s p v R /$ $A^{\prime} l u x C D A B E$ induction but the level of light emitted was $1-2 \log _{10}$ less than in DT 104 strains classified as resistant (Fig. 2b). A semi-qualitative visual examination of RpoS expression was performed in DT 104 strain 41 by adding $\mathrm{H}_{2} \mathrm{O}_{2}$ to bacterial colony mass derived from a nutrient agar plate (Zambrano et al., 1993). The extent of bubbling was similar to that of DT 104 strain 30, suggesting that a sufficient level of RpoS protein expression for hydrogen peroxidase II production was present in strain 41 . When the expression of $s p v R /$ $A^{\prime} l u x$ :: CDABE encoded by pSB368 was determined in isogenic $S$. typhimurium strains of LT2 derivative harbouring different $r p o S$ alleles, three levels of light

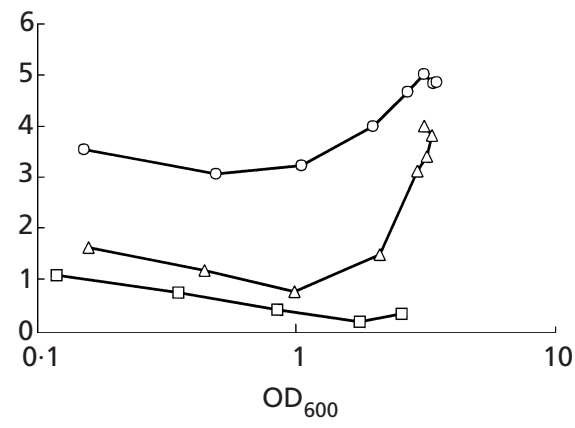

Fig. 3. Expression of the $\sigma^{\mathrm{s}}$-dependent $s p v R / A^{\prime}:: l u x C D A B E$ fusion in $S$. typhimurium strains with an LT2 background but different rpoS alleles: $\chi 4996$ (rpos::bla) ( $\square$ ), $\chi 3000$ (rpos ${ }^{\mathrm{LT} 2}$ ) $(\triangle)$ and $\chi 8000\left(r p o s^{s L 1344}\right)(\bigcirc)$. Results show one representative experiment.

emission were observed (Fig. 3). These results are analogous to three levels of $\beta$-galactosidase activity measured with a spvA-lacZ fusion by WilmesRiesenberger et al. (1997). However, the quantitative aspects of induction were different. A 100-fold induction was measured using the lux fusion (Fig. 3), as compared to the 18 -fold induction seen with the $\beta$-galactosidase fusion (Wilmes-Riesenberger et al., 1997).

\section{rpos loci in DT 104 and PT 4 strains}

The rpoS gene was sequenced in DT 104 strains 30, 11, 10 and 41 and PT 4 strains C, I and E. The rpoS gene in the stress-resistant PT 4 strain $\mathrm{E}$ was $100 \%$ identical in DNA sequence to the rpoS gene of Salmonella Dublin (GenBank accession no. X82129), whereas the two stress-sensitive PT 4 strains both harboured mutations. Strain C contained an insertion (A) at codon 220, causing a frameshift resulting in a stop codon after nucleotide 684. Strain I had undergone a $393 \mathrm{bp}$ inframe deletion beginning at nucleotide 540. The rpoS genes in DT 104 strains 30, 11 and 41 exhibited 100\% identity in nucleic acid sequence to the rpoS gene of $S$. typhimurium C52 (GenBank accession no. X77752). The rpoS gene in DT 104 strain 10, however, contained a single base-pair substitution ( $G$ to $T$ ) at codon 33, changing a GAG codon, specifying glutamic acid to a TAG amber nonsense codon. It is interesting to note that several laboratory strains of $E$. coli including JC7623, AB1157 and RM4606 also contain a mutation at this codon (C to T), also resulting in a TAG amber nonsense codon (Visick \& Clarke, 1997).

\section{DISCUSSION}

S. typhimurium DT 104 and S. enteritidis PT 4 are major foodborne enteric pathogens for humans, with poultry products as significant vehicles of infection. A clear understanding of the factors which determine the survival of the bacteria in relevant environments and their virulence in chickens is important in the identification of control measures. Estimating the possible 
variation in these parameters will also help in risk assessment of salmonellosis.

Previous work on PT 4 demonstrated that naturally occurring strains differed with respect to their resistance to heat, acid, peroxide and airdrying on surfaces, and their virulence in mice and chickens infected orally (Humphrey et al., 1995, 1996, 1998). The studies reported in this paper sought to take the investigations into resistance and virulence of Salmonella spp. further by examining the behaviours of S. typhimurium DT 104 strains and by correlating these with RpoS expression.

The results showed that as with PT 4, DT 104 comprises sensitive and resistant strains when cells are challenged in stationary phase. These results could suggest differences in RpoS expression, and this was explored in several DT 104 and PT 4 strains. In the five sensitive DT 104 and PT 4 strains examined, three harboured mutations in the rpoS gene, while two DT 104 strains had intact rpoS genes and one of those demonstrated a reduced level of RpoS-dependent spvR/A' : : luxCDABE expression. In E. coli, expression of the RpoS protein is known to be primarily controlled post-transcriptionally and evidence for post-transcriptional regulation in Salmonella has also been found (Lange \& HenggeAronis, 1994; Schweder et al., 1996; Pratt \& Silhavy, 1996; Bearson et al., 1996). It is therefore possible that the reduced expression the RpoS-dependent $s p v R /$ $A^{\prime}$ : : luxCDABE fusion in DT 104 strain 11 is due to mutations affecting the translational processing of the RpoS protein or, alternatively, to protein instability. The presence of mutant rpoS alleles has also been investigated in clinical and environmental strains of shiga-like toxin-producing E. coli (Waterman \& Small, 1996). Ten out of 58 strains were acid sensitive, and acid resistance could be restored in six strains when complemented with a functional rpoS in trans, suggesting that at least $10 \%$ of the population could be rpoS mutants. The rpoS allele was sequenced in two acid-sensitive strains and one had undergone a single base-pair deletion resulting in a stop codon after amino acid 28 while the other contained an 11 base-pair duplication resulting in a stop codon after amino acid 77 (Waterman \& Small, 1996). Laboratory strains of E. coli have also been shown to contain mutant rpoS alleles or acquire them through extended culture (Ivanova et al., 1992; Visick \& Clarke 1997; Zambrano et al., 1993) and several of the typical laboratory LT2-derived strains of S. typhimurium contain an rpoS allele with a rare UUG start codon (Wilmes-Riesenberg et al., 1997). The DT 104 strains 11 and 10, found in this study, were initially isolated from human cases of gastroenteritis, while the PT 4 strains $\mathrm{C}$ and I were isolated from chicken carcasses. The rpoS mutation in strain 10 may have arisen during the initial isolation of the strain, although it has maintained its stress sensitivity after trials of extensive subculturing in the laboratory. It is, however, also possible that strains lacking important virulence factors may cause infection, as the development of an infection will, among other things, depend on the status of the host and the amount of inoculum (Picard et al.,
1999). We are currently addressing this issue by examining the RpoS status of colonies arising from the initial isolation plates associated with cases of gastroenteritis.

The DT 104 and PT 4 rpoS mutants were very sensitive to airdrying on surfaces. The trehalose synthesis gene ots $A$ is regulated by RpoS in S. typhimurium (Fang et al., 1996) and trehalose is known to protect cells from drying by stabilizing membranes and enzymes, and this may explain the observation (Potts, 1994). PT 4 strain I, now identified as an rpoS mutant, has also been shown to survive poorly in aerosols (Humphrey et al., 1996).

The pathogenicity of selected DT 104 strains was also examined in point-of-lay commercial hens infected orally. Strains with mutations in the rpoS gene were less frequently found in the tissues of experimentally infected birds and in previous work, the PT 4 strain I (identified as an rpoS mutant in this work) was also less frequently isolated from chicken tissues, particularly those of the reproductive tract (Humphrey et al., 1996). Interestingly, the faecal carriage rate of stress-sensitive strains was not significantly different from those of stress-resistant strains and strain 11 was the only strain found in muscle tissue (Williams et al., 1998). The data from these experiments demonstrate a potentially complex relationship between RpoS expression, pathogenicity and stress tolerance. The level of expression of the RpoS-dependent $s p v R / A^{\prime}:: \operatorname{lu} x C D A B E$ fusion in strain 11 was lower than in the stress-resistant strain 30 , but with a similar induction, while strain 10 encoded a highly truncated protein. However, strain 11 was not significantly less frequently isolated from spleen tissue compared to strain 30 , and strain 11 was also able to invade the reproductive tissues of chicken, in contrast to strain 10. The stress-sensitive strain 41 was absent from ovarian tissues and was recovered from the oviduct of only one of 30 chickens, yet it carries a functional rpoS gene. This suggests it may well harbour mutation(s) in other stress response/virulence genes such as rpoE (Humphreys et al., 1999). Together the data suggest that a functional rpoS gene is necessary but not sufficient for the full virulence of DT 104 in poultry and that molecular determinants other than the RpoS protein play a role.

The differences in the invasiveness into the reproductive tissues between the DT 104 strains did not correlate with the subsequent egg contamination rates reported by Williams et al. (1998). Indeed, the poorly invasive strain 10 produced egg contamination rates as high as many of the other strains, and the stress-sensitive strain 11 produced the highest rates. Clearly, while the RpoS protein is important for colonizing the reproductive tissue in laying hens, the contamination of egg contents appears to be dependent on other undefined molecular determinants.

This present study used chickens. Other work showed that expression of the RpoS protein had no effect on invasiveness into the tissues of day-old chicks (AllenVercoe et al., 1998; Humphrey et al., 1996). Strains with 
normal expression of the RpoS protein are, however, significantly more virulent in orally infected mice (Fang et al., 1992; Humphrey et al., 1996, 1998; WilmesRiesenberger et al., 1997). Thus, the role of the rpoS gene is dependent on the host environment, and while virulence in mice and survival in the environment is highly RpoS-dependent, invasion into day-old chicks may not require RpoS. In mice, the RpoS-dependent effect on virulence is mainly exerted via the activation of the virulence plasmid $s p v$ genes, but rpoS-regulated chromosomally encoded genes also have a contributory role (Fang et al., 1992). The ability of Salmonella strains to invade the liver or colonize the caecum of chickens was, however, not affected by the absence of the virulence plasmid, suggesting that chromosomally encoded rpoS-regulated genes are responsible for the differences in invasiveness observed in chickens (Halavatkar \& Barrow, 1993). Detailed investigation of the role of rpoS in the pathogenicity process has shown that rpoS does seem to be important for colonizing Peyer's patches (Nickerson \& Curtiss, 1997). The process of infection is complex and depends on many factors including LPS, fimbriae, virulence plasmid, toxins and siderophores. Loss of one or more of these may result in loss of virulence depending on the host environment (Cox, 1995).

In this work we have demonstrated that within clinical and environmental strains of S. typhimurium DT 104 significant differences exist in the ability to invade and/or persist in chickens and to survive exposure to heat stress, low $\mathrm{pH}$ and airdrying on surfaces. It remains to be definitively determined whether rpoS nonsense mutations such as those identified in the clinical strains studied here and elsewhere are also present in strains at the point of host infection.

\section{ACKNOWLEDGEMENTS}

We would like to thank Mary Wilmes-Riesenberger for providing strains and Simon Swift for critical comments on the manuscript. This work has been sponsored by the Department of Health, the PHLS and the British Society for the Study of Infection.

\section{REFERENCES}

Allen-Vercoe, E., Collighan, R. \& Woodward, M. J. (1998). The variant $r p o S$ allele of $S$. enteritidis strain $27655 \mathrm{R}$ does not affect virulence in a chick model nor constitutive curliation but does generate a cold-sensitive phenotype. FEMS Microbiol Lett 167, $245-253$.

Altekruse, S. F., Cohen, M. L. \& Swerdlow, D. L. (1997). Emerging foodborne diseases. Emerg Infect Dis 3, 285-293.

Anonymous (1997). Multidrug resistant Salmonella typhimurium. Fact sheet no. 139, Division of Emerging and Other Communicable Diseases Surveillance and Control. Geneva, Switzerland: World Health Organization.

Anonymous (1999). Salmonella infections, England and Wales: reports to the PHLS (Salmonella data set). Commun Dis Rep Rev 9, 10.

Bearson, S. M. D., Benjamin, W. H., Jr, Swords, W. E. \& Foster, J. W. (1996). Acid shock induction of RpoS is mediated by the mouse virulence gene mviA of Salmonella typhimurium. J Bacteriol 178, 2572-2579.

Cox, J. M. (1995). Salmonella enteritidis: virulence factors and invasive infection in poultry. Trends Food Sci Technol 6, 407-410.

Coyle, E. F., Ribeiro, C. D., Howard, A. J., Palmer, S. R., Jones, H. I., Ward, L. \& Rowe, B. (1988). The Salmonella enteritidis phage type 4 infection associated with hen eggs. Lancet ii, 1295-1296.

Fang, F. C., Libby, S. J., Buchmeier, N. A., Loewen, P. C., Switala, J., Harwood, J. \& Guiney, D. G. (1992). The alternative $\sigma$ factor KatF (RpoS) regulates Salmonella virulence. Proc Natl Acad Sci U S A 89, 11978-11982.

Fang, F. C., Chen, C. Y., Guiney, D. G. \& Xu, Y. (1996). Identification of $\sigma^{\mathrm{s}}$-regulated genes in Salmonella typhimurium: complementary regulatory interactions between $\sigma^{\mathrm{s}}$ and cyclic AMP receptor protein. J Bacteriol 178, 5112-5120.

Guiney, D. G., Libby, S., Fang, F. C., Krause, M. \& Fierer, J. (1995). Growth-phase regulation of plasmid virulence genes in Salmonella. Trends Microbiol 3, 275-279.

Gulig, P. A., Danbara, H., Guiney, D. G., Lax, A. J., Norel, F. \& Rhen, M. (1993). Molecular analysis of $s p v$ virulence genes of the salmonella virulence plasmids. Mol Microbiol 10, 825-830.

Halavatkar, H. \& Barrow, P. L. (1993). The role of a 54-kb plasmid in the virulence of strains of Salmonella enteritidis of phage type 4 for chicken and mice. J Med Microbiol 38, 171-176.

Hill, P. J., Rees, C. E. D., Winson, M. K. \& Stewart, G. S. A. B. (1993). The application of lux genes. Biotechnol Appl Biochem 17, 3-14.

Humphrey, T. J., Slater, E., McAlpine, K., Rowbury, R. J. \& Gilbert, R. J. (1995). Salmonella enteritidis phage type 4 isolates more tolerant of heat, acid, or hydrogen peroxide also survive longer on surfaces. Appl Environ Microbiol 61, 3161-3164.

Humphrey, T. J., Williams, A., McAlpine, K., Lever, M. S., GuardPetter, J. \& Cox, J. M. (1996). Isolates of Salmonella enterica Enteritidis PT 4 with enhanced heat and acid tolerance are more virulent in mice and more invasive in chicken. Epidemiol Infect $117,79-88$.

Humphrey, T. J., Williams, A., McAlpine, K., Jørgensen, F. \& O'Byrne, C. (1998). Pathogenicity in isolates of Salmonella enterica serotype Enteritidis PT 4 which differ in RpoS expression: effects of growth phase and low temperature. Epidemiol Infect 121, 295-301.

Humphreys, S., Stevenson, A., Bacon, A., Weinhardt, A. B. \& Roberts, M. (1999). The alternative sigma factor, $\sigma^{\mathrm{E}}$, is critically important for the virulence of Salmonella typhimurium. Infect Immun 67, 1560-1568.

Ivanova, A., Renshaw, M., Guntaka, R. V. \& Eisenstark, A. (1992). DNA base sequence variability in katF (putative sigma factor) gene of Escherichia coli. Nucleic Acid Res 20, 5479-5480.

Lange, R. \& Hengge-Aronis, R. (1994). The cellular concentration of the $\sigma^{\mathrm{s}}$ subunit of RNA polymerase in Escherichia coli is controlled at the levels of transcription, translation, and protein stability. Genes Dev 8, 1600-1612.

Leach, S. A., Williams, A., Davies, A. C., Wilson, J., Marsh, P. D. \& Humphrey, T. J. (1999). Aerosol route of experimental infection enhances the contamination of intact eggs and muscle of experimentally laying hens by Salmonella typhimurium DT 104. FEMS Microbiol Lett 171, 203-207.

Loewen, P. C. \& Hengge-Aronis, R. (1994). The role of the sigma factor $\sigma^{\mathrm{s}}(\mathrm{KatF})$ in bacterial global regulation. Annu Rev Microbiol 48, 53-80.

Mahan, M. J., Slauch, J. M. \& Mekalanos, J. J. (1996). Environmental regulation of virulence gene expression in Escherichia, 
Salmonella and Shigella spp. In Escherichia coli and Salmonella: Cellular and Molecular Biology, pp. 2803-2815. Edited by F. C. Neidhardt and others. Washington, DC: American Society for Microbiology.

Nickerson, C. A. \& Curtiss, R., III (1997). Role of sigma factor RpoS in initial stages of Salmonella typhimurium infection. Infect Immun 65, 1814-1823.

Picard, B., Garcia, J. S., Gouriou, S., Duriez, P., Brahimi, N., Bingen, E., Elion, J. \& Denamur, E. (1999). The link between phylogeny and virulence in Escherichia coli extraintestinal infection. Infect Immun 67, 546-553.

Potts, M. (1994). Desiccation tolerance of prokaryotes. Microbiol Rev 58, 755-805.

Pratt, L. A. \& Silhavy, T. J. (1996). The response regulator SprE controls the stability of RpoS. Proc Natl Acad Sci USA 93, 2488-2492.

Rajashekara, G., Munir, S., Alexeyev, M. F., Halvorson, D. A., Wells, C. L. \& Nagaraja, K. V. (2000). Pathogenic role of SEF14, SEF17, and SEF21 fimbriae in Salmonella enterica serovar Enteritidis infection of chickens. Appl Environ Microbiol 66, 1759-1763.

Rampling, A., Anderson, J. R., Upson, R., Peters, E., Ward, L. R. \& Rowe, B. (1989). Salmonella enteritidis phage type 4 infection of broiler chickens: a hazard to public health. Lancet ii, 436-438.

Schweder, T., Lee, K.-H., Lomovskaya, O. \& Matin, A. (1996). Regulation of Escherichia coli starvation sigma factor $\sigma^{\mathrm{s}}$ by ClpXP protease. J Bacteriol 178, 470-476.

Swift, S. \& Stewart, G. S. A. B. (1994). Luminescence as a signal of spvA expression. In Bioluminescence and Chemiluminescence. Fundamentals and Applied Aspects, pp. 93-96. Edited by A. K. Campbell, L. J. Kricka \& P. E. Stanley. Chichester: Wiley.

Swift, S., Winson, M. K., Chan, P. F. \& 11 other authors (1993). A novel strategy for the isolation of luxI homologues: evidence for the widespread distribution of a LuxR:LuxI superfamily in enteric bacteria. Mol Microbiol 10, 511-520.

Threlfall, E. J., Hampton, M. D., Schofield, S. L., Ward, L. R., Frost, J. A. \& Rowe, B. (1996). Epidemiological application of differentiating multiresistant Salmonella typhimurium DT 104 by plasmid profile. Commun Dis Rep Rev 6, R155-R159.

Visick, J. E. \& Clarke, S. (1997). RpoS- and OxyR-independent induction of HPI catalase at stationary phase in Escherichia coli and identification of $r p o S$ mutations in common laboratory strains. J Bacteriol 179, 4158-4163.

Wall, P. G., Morgan, D., Lamden, K., Ryan, M., Griffin, M., Threlfall, E. J., Ward, L. R. \& Rowe, B. (1994). A case control study of infection with an epidemic strain of multi-resistant Salmonella typhimurium DT 104 in England and Wales. Commun Dis Rep Rev 4, R130-R140.

Waterman, S. R. \& Small, P. L. C. (1996). Characterization of the acid resistance phenotype and rpoS alleles of shiga-like toxinproducing Escherichia coli. Infect Immun 64, 2808-2811.

Williams, A., Davies, A. C., Wilson, J., Marsh, P. D., Leach, S. \& Humphrey, T. J. (1998). Contamination of the contents of intact eggs by Salmonella typhimurium DT 104. Vet Rec 143, 562-563.

Wilmes-Riesenberger, M. R., Foster, J. W. \& Curtiss, R., III (1997). An altered $r p o S$ allele contributes to the avirulence of Salmonella typhimurium LT2. Infect Immun 65, 203-210.

Zambrano, M. M., Siegele, D. A., Almirón, M., Tormo, A. \& Kolter, R. (1993). Microbial competition: Escherichia coli mutants that take over stationary phase cultures. Science 259, $1757-1760$.

Received 6 December 1999; revised 20 June 2000; accepted 22 August 2000. 